\title{
Erratum: Glucose-tolerant $\beta$-glucosidase retrieved from a Kusaya gravy metagenome
}

\section{Frontiers Production Office *}

Frontiers Production Office, Frontiers, Lausanne, Switzerland

Keywords: $\beta$-glucosidase, cellulosic biomass, enzymatic saccharification, metagenome, substrate inhibition, product inhibition

\section{An erratum on}

Glucose-tolerant $\beta$-glucosidase retrieved from a Kusaya gravy metagenome by Uchiyama, T., Yaoi, K., and Miyazaki, K. (2015). Front. Microbiol. 6:548. doi: 10.3389/fmicb.2015.00548

Reason for Erratum:

Due to a typesetting error, the first author affiliation was listed incorrectly as Department of Medical Microbiology, University of Groningen, University Medical Center Groningen, Groningen, Netherlands.

The correct affiliation is: Bioproduction Research institute, National Institute of Advanced Industrial Science and Technology Tsukuba, Ibaraki, Japan.

The publisher apologizes for this mistake. This error does not change the scientific conclusions of the article in any way.

Original article was updated.

Copyright () 2015 Frontiers Production Office. This is an open-access article distributed under the terms of the Creative Commons Attribution License (CC BY). The use, distribution or reproduction in other forums is permitted, provided the original author(s) or licensor are credited and that the original publication in this journal is cited, in accordance with accepted academic practice. No use, distribution or reproduction is permitted which does not comply with these terms. 